\title{
A New Hypothesis of Duchenne Muscular Dystrophy
}

\section{Leonora Grinio}

Department Ministry Health, Moscow University Medicine and Dentistry, Moscow, Russia

\section{Email address:}

griniol@yandex.ru

\section{To cite this article:}

Leonora Grinio. A New Hypothesis of Duchenne Muscular Dystrophy. American Journal of Psychiatry and Neuroscience. Vol. 9, No. 2, 2021, pp. 25-30. doi: 10.11648/j.ajpn.20210902.11

Received: November 24, 2020; Accepted: December 15, 2020; Published: April 13, 2021

\begin{abstract}
Duchenne Muscular Dystrophy is the product the mutation the gene-dystrophine and appearing defective protein dystropnin. Its function is unclear, suppose protection membranes during the contraction-relax skeletal muscles. The cytoplasmic dystrophin acts as the complexes with different proteins inside and around membranes, which are placing in skeletal muscls, heart, different regions brain, internal organs, their function unclear. The high activity enzyme creatin-kinasa in the patients blood is the known fact which is usually explain damage of the process contraction-relax skeletal muscles. The surprising activity enzyme $-23000 \mathrm{M} \mathrm{E}$ was found by author at large families with typical pedigree where have some patients and some boys without signs muscle weakness. There were 4 boys 12-22 months life during forming walk, later these boys were diagnosed as Duchenne Muscular Dystrophy patients. Such activity I did not find in literature. Usually the highest activity enzyme 10 000-12 $000 \mathrm{ME}$. This fact testify the simultaneously damage many membranes on large territory, it permits suppose organized damage membranes. Author believe all complexes normal dystrophines may work as one System, beginning learn walk and finishing as age myopathy after 60 years. Suppose the System was ancient and appeared when movements become intensive and one gene utrophine/dystrophine turned out in two genes: utrophin and dystrophin. Dystrophin signal communication is known, but its investigation has begun and showed complex signaling pathways. It is possible to suppose that the first stage of the disease is damage signaling ways. Damage homeostasis and membranes is the second stage. There are deep changes of metabolism: decreasing true muscle proteins, phospholipids, increasing hormones, appearing hyper aminoaciduria. Apoptosis - the three stage of the disease and general destructive factor which turn out pathologic process to the fatal end. Apoptosis hinder all tryings organism to interrupt pathological process and therapeutic trying. Apoptosis can not stop once it began. All three stages have place in preclinical time. The clinic symptoms express destruction more the half skeletal muscles, severe damage metabolism, damage system protection membranes and can not be onset of the disease. The important problem of the disease - studying interaction dystrophin-complexes with membranes during physical stress, signaling ways. Two factors determinate rapid course: damage D-System and apoptosis.
\end{abstract}

Keywords: Dystrophin, Creatinkinasa, Phospholipids, Apoptosis

\section{Introduction}

At the middle of 19 th century Guillaume- Benjamin Duchenne studied a form skeletal muscular pathology in boys named it "Pseudohypertrophic Paralysis" because the patients looked as athletes, but could not walk and were intellectual be backward. He did not find any pathology the central nervous system, hypertrophies of skeletal muscles turned out pseudohypertrophies and G. B. Duchenn defined it as disease of skeletal muscles. The name of the disease: progressive muscular atrophy or muscular dystrophy determinate for long time the investigation skeletal muscles and delay studying the disease. Damage brain was ignored.

In 1968 L. Kunkel described the gene-dystrophin. This gene is the longest in the human genome, encompassing 2, 6 million base pairs of DNA and containing 79 exons. The product of the gene -protein-dystrophin (D) was described in 1987 y. E. Hoffman [4]. Now there is much information concerning of $\mathrm{D}$, which don't exist isolated, it forms tightly associated complexes [1-10]. The dystroglucoprotein complex - DGC- the most studying, 
plays a mechanical function in stabilizing the sarcolemma against stresses during muscles contraction; role scaffold in neuromuscular junctions; the general function is the connection the cytoskeleton to the extracellular matrix. Other complexes D are studying, its role as mechanical component of cell in signaling function The deficiency D skeletal muscles reduces muscle stiffness, increases sarcolemma deformability, membranes abnormal permeability [10-15]. It is known that $D$ present in the brain among the cortical neurons, hyppocamp, Purkinje cells, astrocytes, blood-brain barrier, but its function is unclea [15-29, 38-47] DMD has three symptoms: damage skeletal muscles, brain, heart, but every symptom is studying apart, the great attention devote the skeletal muscles. The disease has not clear pathogenesis and effective treatment. Based on the analysis the results of studying DMD and own experience I suggest a new hypothesis for discussion. Before formulate the hypothesis necessary introduce the general facts of the investigation.

\section{Material and Infer}

The time onset the pathologic process of the disease has the important meaning, because permit to understand essence the disease. Traditionally the appearing clinical symptoms of the muscular weakness of the patients 3-5 years old - the time of onset pathologic process, but the clinic symptoms cannot be criterion because they appear after the loss mass of skeletal muscular and after the large changes of metabolism. I have summarized the results of my biochemical investigation the patients 3-5 years of life as the scheme pathological process. [32]

Table 1. Biochemical parameters the patients with DMD [32].

\begin{tabular}{lll}
\hline tissue & increase & decrease \\
\hline Blood & total lipids, activity of enzymes: creatinkinasa, aldolasa, Hormones: ACTG, cortisol & phospholipides \\
Muscles & collagen, total lipids & carnosin, myosin, myoglobin, phospholipides \\
Urine & Hyper aminoaciduria creatinuria & \\
\hline
\end{tabular}

The table 1 shows the deep changes of metabolism: decreasing true muscle proteins, phospholipids, increasing hormones, enzymes in blood, appearing hyper aminoaciduria. I was shocked when I saw the loss contractility and grey color skeletal muscles the patients 4 years old during biopsy. The presented data shows that this period is not the onset of the disease.

The onset of the disease I revealed during the scientific travel at retired places. Trying to reveal ill boys in the large families with DMD I used the creatin-kinase (CK) test and found the highest activity creatin kinasa 23000 and 21000 $\mathrm{ME}$ in 4 boys from 14 months to 2 years old, later the genetic analysis confirmed DMD in these boys. One family was the russian, another was the tadjik. This activity $\mathrm{CK}$ was surprising, usually the maximal activity CK $10000-12000$ ME in the patients 3-5 years old, 3 000-5000 ME 7-9 years old and 1000-500 ME - 12 years old Figure 1.

Index $23000 \mathrm{ME}$ activity $\mathrm{CK}$ point to breaking many membranes because only the skeletal muscles give not such figure., as have shown results of studying enzymes J. Dreyfus and G. Shapira (36). The graphic shows the meaning CK for the diagnosis, prognosis, definition rapid course disease, but the general meaning - opening onset the disease.

The surprising CK, destroy many membranes, connection the onset of the disease and the onset walking permit suppose existence the System unites the whole dystrophines [32]. This System stabilize membranes during stress.

Like symphonic orchestra, where each instrument has own party, different isomers dystrophines have own party, but together they express one idea, one melody, one general aim cover membranes during physical stress Only all family dystrophines may do this task, like only big orchestra may express idea compositor.

I suppose appearing the System was at early vertebrates, when one gene utrophin-dystrophin turned out in two genes utrophin and dystrophin, May be the gene-dystrophine is the longest in man genome because regulation $\mathrm{D}$ require it. System D has onset one year of life and suppose has the end at 60-70 years old, because manifestations of the myopathy of old ages repeats the same symptoms muscular weakness, damage coordination and the histologic picture of the skeletal muscles.

\section{Discussion}

G. Shapira and J. Dreyfus in 1964 y. wrote in their monography Biochemistry Myopathy: "Muscular dystrophy is a muscualar disease, but it is by no means proved that origin of the disease is in the muscles itself [37]. However this disease prize now as muscle pathology.

DMD has three clinic symptoms: damage skeletal muscles, heart, brain. These symptoms are three components of movements, all three has defective D.

My idea of System D help to understand large spreading D, present D at optical and acoustic analysators, which signals can to increase or stop movement. Stress touch many organs as lien, lungs, hepar, which are necessary during stress. [32].

Different age groups the patients with Duchenne Muscular Dystrophy.

Studying role D in skeletal muscles show the part in mechanical stability costamer, protect process contractionrelax and estimate D as the structure protein but don't explain rapid course the disease.[32-37]

The question -what determinate the rapid pathological temp the disease is unclear.[60-77]

I suppose hypoxia and apoptosis the cause of rapid temp of the pathological process. For the classic variant DMD the rapid course of the disease is typical, but there are some 
variants with mild course and late onset, possible organism can delay development of apoptosis.

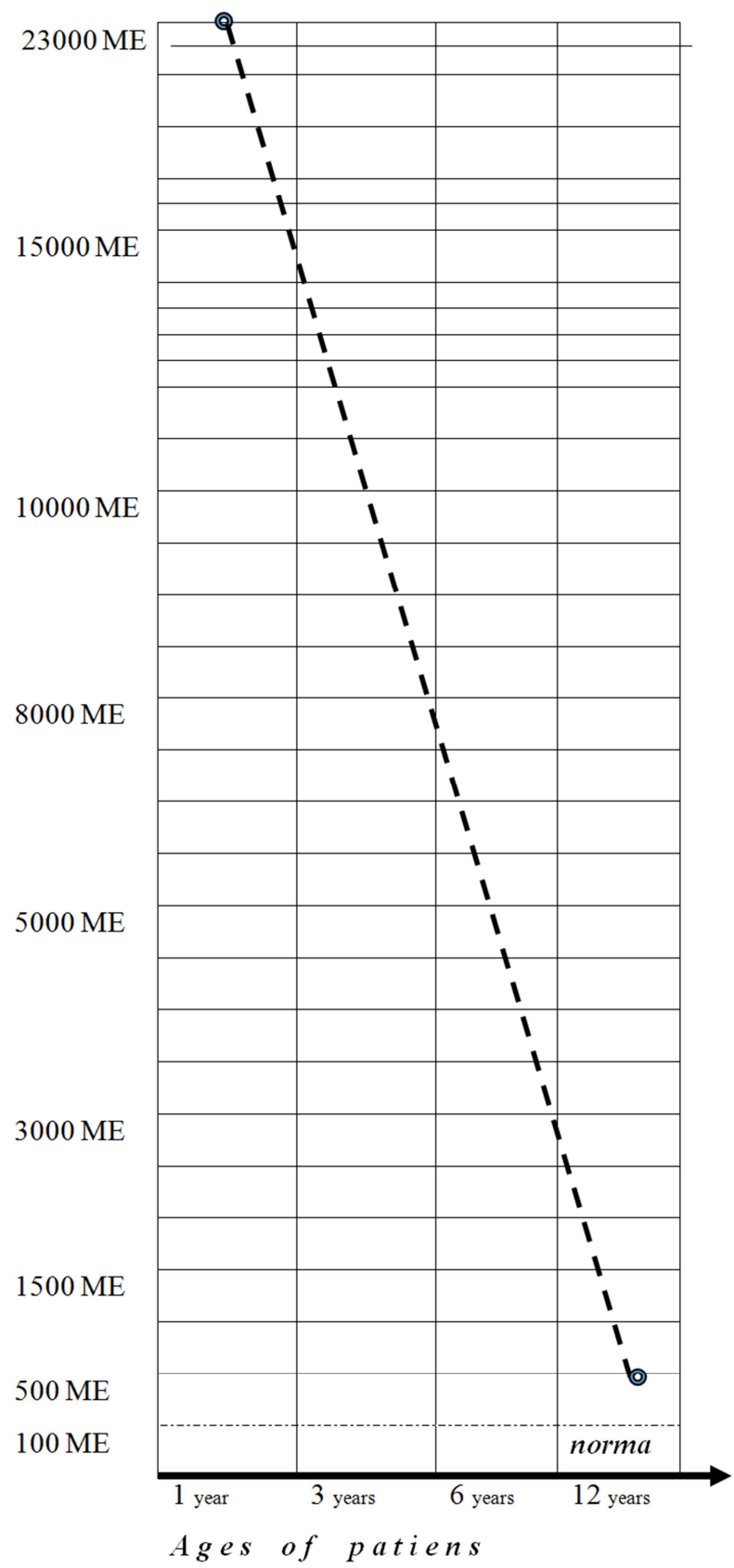

Figure 1. Activity Creatinkinasa (32)

I suppose, that the role the pathology of the lipid metabolism did not prize, though changes this metabolism are expressed,; the appearance of the patients, the deposit lipids as pseudohypertrophies in many skeletal muscles, tongue, internal organs. May be conflict the complex betadystroglucan with phospholipids membrane is a key component of the pathologic process [32].

Apoptosis is the programm death of cells itself or from cells of the immune system. Apoptosis occurs when cells existence uselessly for organism. The initiative of apoptosis is regulated intracellular signal when cells in stress.
Apoptosis is the highly regulated process and cannot stop once it has begun. [47-51] Apoptotic markers: DNA fragmentation, caspases activation, cytochrome c release, mRNA decay are revealed at model mdx, at the patients with DMD. The morphologic investigation the skeletal muscles of the patients show the typical changes: cells decreased, round of, condensation chromatin The question of apoptosis or necrosis is discussed, but necessary take into consideration the stage of the disease - the onset of the disease accompany the signs of apoptosis, the late stage the necrosis. [52-60]

So, pathological process DMD has. some stages, see schema 2.

\section{Conclusion Hypothesis}

Duchenne disease begins as destroy the System Dystrophines. This System unite all dystrophines placing everywhere. Normal work System - stabilize membranes during stress. Defective dystrophines damage work System, membranes. Breaking membranes excites disbalans metabolism, appear hypoxia. Dangerous situation excite apoptosis. Apoptosis - the general factor destroy metabolism which lead organism to fatal end.

Two factors determinate the disease-damage System D and apoptosis.

In the future is necessary: 1 studying apoptosis and possibilities organism delay it. 2- studyng the dysrophine complexes in brain, heart. 3- studyng connection phospholipids membranes and dystrophine.

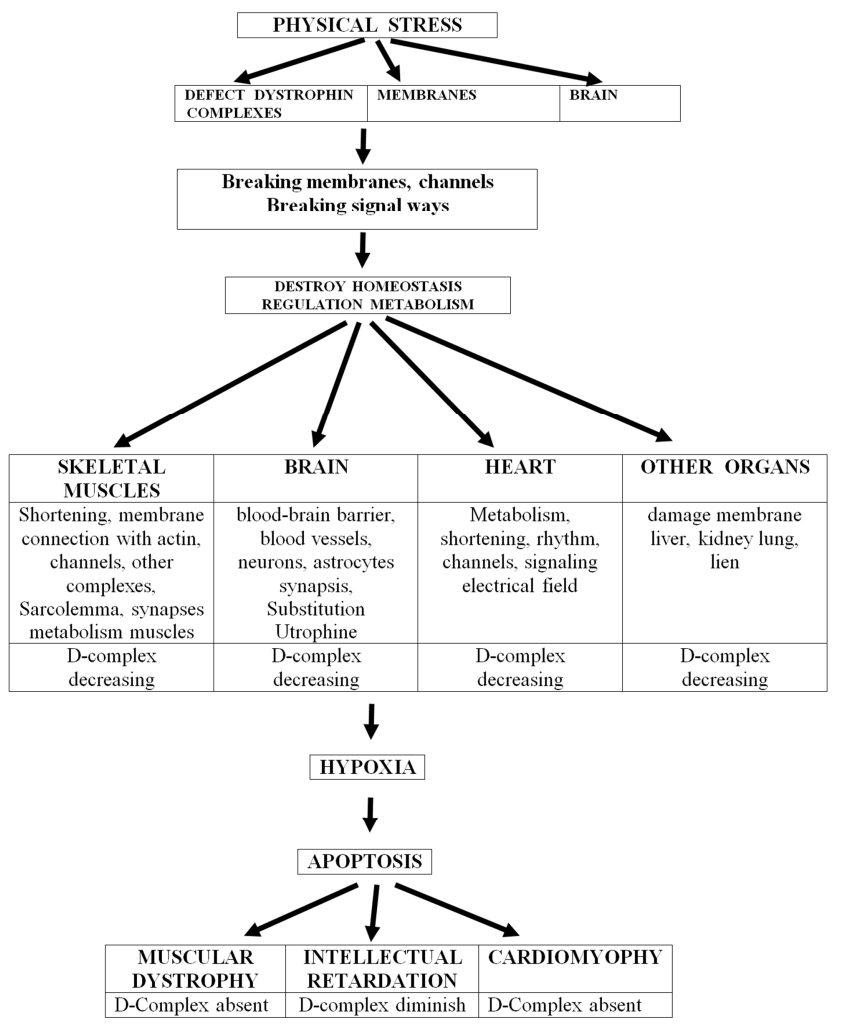

Figure 2. Pathogenesis Duchenne Disease. 


\section{Resume}

Duchenne Muscular Dystrophy - a neuromuscular disease- has three clinical symptoms: damage skeletal muscles, heart and brain, the last symptom was marked Duchenn. The symptoms are three components of movements. The onset of the disease reveals by the creatinkinasa-test $(23000 \mathrm{ME})$ during beginning walking. The test testify damage membranes on large territory because only skeletal muscles cant do it. Author believe the damage membranes connect with destroy System, units the whole dysrophines. System stabilize membranes during physical stress. Defective dystrophines destroy work System and membranes. This situation not dangerous but appear apoptosis, which is the general factor leading organism to fatal end.

Two factors determinate course the disease: damage system dystrophines and apoptosis.

\section{References}

[1] Kunkel L. et al. Analysis of deletions in DNA from patients with Becker and Duchenn Muscular Dystrophy. Nature 1986, $322,73$.

[2] Furakawa T., Peter. The Muscular Dystrophy and related disorder. JAMA 1978, 239, 1654-1659.

[3] Emery A., The Muscular Dystrophy. Lancet. 2002, 359, 687695.

[4] Hoffmann E., Brown R, Kunkel L. Dystrophin: protein product of Duchenne muscular dystrophy. Cell, 1987, 51, 919928.

[5] -Koenig M. Kunkel L/ detailed analysis of the rapid domainof dystrophin reveals four potentialhinge segmsnts that may confer flexibility J/Biol. Chem. 1990, 265, 8. 4560-4566.

[6] Rumeir E. Winder S. Hubert J. Dystrophin. 2012 FEBS Lett. 586, 2717-2719.

[7] Blake D., Weir A. Newey S. Davies K. Function and genetics of dystrophin and dystrophin-related proteins in muscles. Physiological Rewiews 2002, 82, 2291-3.

[8] Lidov H., Byers T., Kunkel L., The distribution of dystrophin in the murine central nervous system cortical neurons. Nature. $1990,348,72-8$.

[9] Goldstein J., Mc Nally E., Mechanism of muscle weakness in muscular dystrophy. Archive 2010, 136, 1-29.

[10] Rubakova I., Humston J., SonnemannK., Ervasti J. Dystriophin and Utrophin Bind Actin trough distinct modes of contact., J. Biol. Chem. 2006, 281, 15, 9996-10001.

[11] Piluso G., Aurino S., Veechio B., NigroV., Mendelian bases of myopathies, cardiomyopathies and neuromyopathies. Acta Myologica. 2010, 29, 1-20.

[12] Piluso G., Mirabella M., ei al. Gammal-and gamma 2syntropins, two novel dystrophin-binding proteins localized in neuronall cells. J. Biol. Chem., 2000., 275., 15851-158860.

[13] Van Putten, Kumar D., Van Ommen., Functional and pathological comparison of mouse-models for Duchenne Muscular Dystrophy. Acta Myologica. 2010, 29, 138-139.

[14] Zhong J et al. Genetic analysis of the D -gene in children with DMD and Becker muscular dystrophy., Muscle, Nerve, 2017 $56,11,117-1214$.

[15] Sekiguchi M., Zushida K., et al. A deficit of brain dystrophin impairs specific amygdala GABA ergictransmission and enhances defensive behavior in mice. Brain, 2008., 10.

[16] Goodnough C., Ying Gao. Lack of dystrophin results in abnormal cerebral diffusion and perfusion in vivo disrubtion of blood-barrer. Neurolmage 2014. 102, 2 809-816.

[17] Godfrey C., Muses S., et al.,. How much dystrophin is enough: the physiological consequences of different levels of dystrophin in the mdx mouses. Hum. Mol. Genet. 2015, 1, 24. 4225-37.

[18] Gee S. Madhavan R. Lesinson S. et al. Interaction of Muscle and brain sodium channels with multiple members of the syntropin family of dystrophin associated proteins. J. Neuroscience 1998, 18, 1, 128-127.

[19] Niels B., Takedo S., Yokota T. Nonmechanical rols of Dystrophin and associated proteins in exercise neuromuscular junctions and brain Brain Sci, 2015. 5. 275-298.

[20] Sojos V., Curto M., Reali C., GremoF., Developmentally regulated expression and localization of dystrophin and utropin in the human fetal brain. Mech Ageing Dev. 2002, 123, $5,455-62$.

[21] Koenig X., Ebner J., Hilber K., Voltage-dependent sarcolemmal ione channels abnormalities J. Mol. Sci. 2018, 19, 11,3296 .

[22] van Putten M., van Pul, Hulsker M., Low dystrophin levels in heart can delay heart failure in $\mathrm{mdx}$ mice. J, Mol. Cellul. Cardiology 2014, 1, 009.

[23] Wickell R., Kihlgren M., et al. Specific cognitive deficits are common in children with Duchenne Muscular Dystrophy. Dev. Child. Neurol 2004, 46, 154-9.

[24] Hendriksen R., Schipper S., Hoogland G., Dystrophin distribution and expression in human. 2016. Cell Neuroscience, 2, 00174.

[25] Waite A., Blake D., Brown S., The dystrophin -glucoprotein complex in brain development and disease. Neurosciences 2012, 35, 8, 497-96.

[26] Deisch J. Swasman P. Development in Health and Disease. Pediatric Neurology. 2017, 6, 1029-310.

[27] KimT, W, Wu, K., Black Defiency in brain sinaptic dystrophin in human Duchenne Muscular Dystrophy. Ann. Neurol. 1995, 38, (3) 446-49.

[28] Culligan K., Glover L., Dowling P. Brain dystrophinglucoprotein complex persistent expression of B-dystroglucan impaired oligolregulation of Dp71 and up-regulation of utropin in animal models. Cell Biology 2991.

[29] Brown S., Lucy J., "Dystrophin”. 1991. Cambridge University Press.

[30] Darras B., Kunkel L., "Dystrophinopathies" in Neuromuscular Disorder of Infancy. 2011 chapter 107, 684-697. 
[31] Haenggi T., Fritschy J., Role of Dystrophin and utropin for assembly and function of the dystrophin glucoprotein complex in non-muscle tissue. Cell. Mol. Life Sciences 2006, 69, 14, 1614-3.

[32] Grinio L.,. Duchenne Myodystrophy. Russ. monografy pub. НГМА, 1998, 1-100.

[33] Grinio L., Pathogenesis of Duchenne Muscular Dystrophy. Russ. J. Neurol. Psych. 2019, 1 19, 3, 79-81.

[34] Escolar D., Leshner R., Treatment and management of Muscular Dystrophy. In "Neuromuscular Disorder of Infancy". 2011, 343-372.

[35] Kogelman B,., Khmelinski A., Verhaat I. Influence of fulllength dystrophin on brain volumes in mouse models of Duchenne Mudcular Dystrophy. $2018 \mathrm{http}^{\wedge} 11 \mathrm{org} / 10$. 1371/journal pone 0104636

[36] Nicols B. Takeda S. Yokota T. Nonmechanical roles of Dystrophin and associated proteins in exercise Brain. Sci. 2015, 5, 275-281.

[37] Dreyfus J. Shapira G. Biochemisytry of hereditary of Myopathies. 1963, 1-14.

[38] Daoud F., Candelario-Martinez A., Role of mental retardation associated dystrophin-gene product Dp71 in excitatory synapse organization synaptic organization, synaptic plasticity and behavioral functions. PLOS One 2009, 4, 8, 6.

[39] Bresolini N., Castelli E., Comi G. et al. Cognitive impairment in Duchenne Muscular Dystrophy. Neuromusculat Disorder, 1994, 4, 359-69.

[40] Fitzpatrik C., Barry C., Garvey C., Psychiatric disorder among boys with Duchenne Muscular Dystrophy. Dev. Med. Child Neurology. 1986, 399, 194-210.

[41] Anderson J., Heads S., Roe E., Morley J., Brain function in Duchenne Musular Dystrophy., Brain, 2002, 125, 4-13.

[42] Tracey I., Dunn J., Radda G., Brain metabolism is abnormal in the mdx model of DMD., Brain., 1996., 119., 1039-44. 9. Wicksell R., Kihlgren M et al. Specific cognitive deficits are common in children with Duchenne Muscular Dystrophy. Dev. Med. Child Neurol. 2004, 46, 154-9.

[43] Nigro V., Okozaki Y. ei al. Identification of the Syrian hamster cardiomyopathy gene. Hum. MoL. Genet. 1997, 6, 601-07.

[44] Sekiguochi M., Zushide., K., Yoshida M. A deficit of brain dystrophin impairs specific amygdala GABAergic transmission and enhances defensive behavior in mice. Brain 2009, 132, 1, 124-135.

[45] Aleman V., Osorio B., Chavez, O., Subcellular localization of Dp71 dystrophin isoforms in cultured hippocampal neurons and forebrain astrocytes. Histochemistry and Cell Biology $2007,115,3,243-2526$.

[46] Anderson J., Head S., Morley J., Long-term depression is reduced in cerebellarar Purkinje cells of dystrophin-deficient mdx mice. Brain. Research 2009. 19, 1-2, 289292.

[47] Banks. G., Gregorevic P., Allen J., Finn E. Chamberlain J. Functional capacity of dystrophins carrying deletions in the Nterminal actin-binding domain. Human Molecular Genetics 2007, 16 (17), 2105-2113231.

[48] Abatado J. Apoptosis, function and regulation of cell death.
Res. Immunol. 1996, 147, 443-456.

[49] Savitz S., Daniel B., Rosenbaum M., Apoptosis in neurological siseases., Neurosurgery 1998, 42, 555-72.

[50] Arends M. Wyllie A., Apoptosis, Mechanism and role in pathology 11 Int. Rev. Exp. Pathol. 1991, 32, 223-2.

[51] Tang H. Cell survival DNA damage and oncogenic transformation after a transiet and reversible response. Mol. Biol. Cell 2012, 23, 2940-52.

[52] Borras G. Programmed cell death in plants and animals. Biotechnologia Aplicada. 2006, 23, 1-10.

[53] Morikawa Y., Heallen T., Leach J., Xiao Y., Morton J. Dystglucoprotein complex sequesters to inhibid cardiomyocyte proliferation. Nature 2017. 13, 547, 227-231 62., Soyos V., Curto M., Reali C., Grenio F. Developmentally regulated expression and localization of dystrophin and utropin in the human fetal brain. Mech. Ageing Dev. 2002, 123, 5, 455-62.

[54] Milad. N., White Z., Tehrani A., Rossi F., Increased plasma lipid levels in the mdx model. Nature 2017. 13, 547, 227-231.

[55] Goodnough c., Gao Y,. Qutaish Q., Lack dystrophin results in abnormal cerebral diffusion and perfusion in vivo., Neuromage 2014, 192, 2, 809-816.

[56] Brown S., Lucy J.,. Expression D-complex in brain. In book Dystrophin 1997, 13, 1-100.

[57] Tompkins A., Muscle Physiology and Patholoy of Muscular Dystrophy 2010 Everglades University Biology.

[58] Kobayshi Y., Camplell K. The mechanistic basis of maintaining muscle membrane integrity. Muscle Nerve 2012.

[59] Ujihara Y., et al. Elimination of fukutin reveals cellular and molecular pathomechanizms in muscular dystrophyaccociated heart failure. Nature. Communications 2020, 10, 1038-40.

[60] Santos R. New variants challenges and pitfalls in Duchenne Muscular dystrophy genotyping, implications in diagnoses, prognosis and therapy. J. Human Genet. 2014, 59, 454-454.

[61] Luke M., Haraguchiln M, Chamberland S. Dissecting and signaling and mechanical function of the dystrophin in muscular mechanisms of muscular dystrophy. JCellScience 2006, 118, 1537-46.

[62] Thomas G., Sander M., Lau K., HuangP., Impaired metabolic modification of alpha-adrenergic vasoconstriction in dystrophin-deficient skeletal muscles. Proc. Natl. Acad. Sci. 1998, 95, 554-560.

[63] Hoffman E. New research increases understanding of Duchenne Muscular Dystrophy. Amr. J. Human Genet. 2016, 8, 23-28.

[64] Constantin B., Dystrophin complex function as a scaffold for signalic proteins. Biochem et Biophy/s. Acta (BBA) Biomembranes. 2014, 1838, 2, 625.

[65] Brown S., Dystrophin and Utrophin. Genetic analysis of their role in skeletal muscles. Microse. Res. Tech. 2000, 48, 3-4, 155-61.

[66] Judge L., Haraguehiln M., Chamberlain S., Dissecting the signaling and mechanical functions of DGC J. Cell SCI. 2006 $15,119,1537-46$. 
[67] Rondo T. A. The dystrophin-glucoprotein complex cellular signaling and regulation of cell survival in the muscular dystrophy. Muscle. Nerve 2001, 24, 1575-159.

[68] Gambardelle A. Dystrophin distribution and expression in human and experimental temporal lobe. Epilepsy Research University Catanzago., 2019. 153. 49-58.

[69] Culligan K., Beta-Dystrobrevin and Dystrophin in brain neurons. Cell Biology 2001, 2, 2-10.

[70] Goldstein J,. Mc Nally E. Mechanism of musle weakness in muscular dystrophy Archive 2010, 136, 1-129.

[71] Ujhara Y. Estimation of fukutin reveals cellular and molecular pathomechanims in muscular dystrophy. Nature 2020, 10, 1038-41.

[72] Vican S., Piccini G., Mercuri E,. Alfieri P. Implacit learnig deficit in children with Duchenne Muscular Dystrophy: evidence for a cerebellar cognitive impairtment Nature 2018 10,82 .
[73] Pins A., Spitali P., Circulating biomarkers for Duchenne Muscular Dystrophy. J. Neuromuscular Disord 2015, 2, 4958.

[74] Allen D., Whitehead N,. Frochner S., Absence of Dystrophin disrubtion skeletal muscle signaling: roles of $\mathrm{Ca} 2$, reactive oxygen species, nitric oxide in the development of muscular dystrophy. Physical Rew. 2016, 96, 253-305. 9975Guiraud S.

[75] Davies K. Regenerative biomarkers for Duchenne Muscular Dystrophy. Neural. Regen Res. 2019, 14, 8, 1317-1320.

[76] Grounds M., Ferrill J., Al-Mehdani B., Duong M. Biomarkers for Duchenne Muscular Dystrophy: myonecrosis, inflammation, and oxidative stress. Dis. Model. Mech. 2020, 2, 13,1242 .

[77] Morikawa Y., Heallen T., Leach J. Xiao Y. Martin J. Dystglucoprotein Complex sequesters Yap to in cardiomyocytes. Nature 2017, 13, 547, 227-231. 